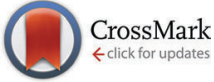

Cite this: New J. Chem., 2016, 40, 2920

Received (in Montpellier, France) 14th October 2015 . Accepted 18th January 2016

DOI: $10.1039 / c 5 n j 02839 f$

www.rsc.org/njc

\title{
Synthesis of ester-substituted dihydroacridine derivatives and their spectroscopic properties $\uparrow$
}

\author{
Ryota Suzuki, Reiki Tada, Takumi Hosoda, Youhei Miura and Naoki Yoshioka*
}

Three dihydroacridine derivatives, 2,7-bis(4-methoxycarbonylphenyl)-9,9-diphenyl-9,10-dihydroacridine (1), 2,8-bis(4-methoxycarbonylphenyl)-10,10-diphenyl-5,10-dihydrophenazasiline (2), and 2,7,9,9-tetraphenyl9,10-dihydroacridine (3), were prepared and their spectroscopic properties were investigated. These compounds exhibited relatively high quantum yields in a range of solvents. The emission spectra of 1 and 2 displayed large solvatochromic shifts, while the fluorescence solvatochromic behavior was not observed in 3. The intramolecular charge transfer (CT) process from the electron donating moiety at the $\mathrm{NH}$ site to the electron withdrawing ester moiety occurs in the excited states of $\mathbf{1}$ and $\mathbf{2}$. The increase in the dipole moment induced by the CT process was determined to cause the positive fluorescence solvatochromism. The differences between the excited and ground state dipole moments based on the Lippert-Mataga expression were estimated. The effect of the push-pull substitution in the dihydroacridine $\pi$-conjugated system was also discussed using a computational method.

\section{Introduction}

Environment-sensitive fluorescent dyes are an interesting class of molecules exhibiting unique spectroscopic properties depending on the properties of their surroundings such as solvent polarity. ${ }^{1}$ Typical examples of these solvatochromic fluorophores are 4-dimethylamino phthalimide (4-DMAP), ${ }^{2}$ 2-propionyl-6-dimethylaminonaphthalene (PRODAN), ${ }^{3}$ 4-amino-1,8-naphthalimide (4-DMN), ${ }^{4}$ and 6- $N, N$-dimethylamino-2,3-naphthalimide (6-DMN) ${ }^{5}$ having a push-pull substituted $\pi$-conjugated system. ${ }^{6}$ It is also known that bridging an aromatic ring by a Si atom influences the spectroscopic property due to the hyperconjugation and perturbation of the electronic structure that often enhances the fluorescence intensity. ${ }^{7}$

During the course of the study on the synthesis and physicochemical properties of aromatic nitroxide derivatives having rigid 1,2-dihydroquinole ${ }^{8}$ and 9,10-dihydroacridine ${ }^{9}$ backbones, we observed the fluorescence of phenyl substituted 9,10-dihydroacridine, which prompted us to investigate the structure-function relationship in 9,10-dihydroacridine derivatives because they have a planar backbone due to the cross-linked diphenylamine whose rigid structure is suitable for fluorescent molecules. In the present paper, we describe the synthesis of ester substituted derivatives, 2,7-bis(4-methoxycarbonylphenyl)-9,9-diphenyl-9,10-dihydroacridine

Department of Applied Chemistry, Faculty of Science and Technology, Keio University, Yokohama, 223-8522, Japan. E-mail: yoshioka@applc.keio.ac.jp $\dagger$ Electronic supplementary information (ESI) available: Analytical and spectral date, details of computational data and ${ }^{1} \mathrm{H}$ and ${ }^{13} \mathrm{C}$ NMR spectra are available. CCDC 1417594 (1) and 1417595 (2). For ESI and crystallographic data in CIF or other electronic format see DOI: $10.1039 / \mathrm{c} 5 \mathrm{nj} 02839 \mathrm{f}$
(1) and its silicon containing analogue 2,8-bis(4-methoxycarbonylphenyl)-10,10-diphenyl-5,10-dihydrophenazasiline (2), and their spectroscopic properties in comparison with that of 2,7,9,9tetraphenyl-9,10-dihydroacridine (3) (Fig. 1).

\section{Results}

\section{Synthesis}

The dihydroacridines, 1 and 3, were prepared in four steps from 9,9-diphenyl-9,10-dihydroacridine $(4)^{10}$ according to Scheme S1 $(\mathrm{ESI} \dagger)$. The aromatic substituent groups were introduced by the Suzuki-Miyaura cross-coupling reaction with good yields between the 2,7-dibromo-9,9-diphenyl-9,10-dihydroacridine-10(9H)-carboxylic acid tert-butyl ester (6) with the 4-methoxycarbonylphenylboronic acid pinacol ester and the phenylboronic acid. 2,7-Dibromo-9,9diphenyl-9,10-dihydroacridine (5) was protected with the tertbutoxycarbonyl group to enhance the reactivity. The synthetic scheme of the 2,8-diaryldihydrophenazasiline derivative, 2, is outlined in Scheme S2 (ESI $\dagger$ ). 2 was prepared in six steps from 2,2' $, 4,4^{\prime}$-tetrabromodiphenylamine (9). ${ }^{11}$ The dihydrophenazasiline

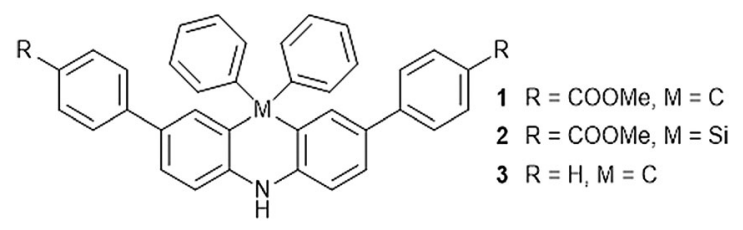

Fig. 1 Chemical structures of 1, 2, and $\mathbf{3}$. 
skeleton was constructed by the reaction between the $o$-dilithiodiphenylamine derivative ${ }^{12}$ and $\mathrm{SiPh}_{2} \mathrm{Cl}_{2}$, while the $p$-methoxybenzyl group was used as the protecting group for the $\mathrm{NH}$ site. The electron withdrawing group could be introduced by the Suzuki-Miyaura cross-coupling reaction via the same Scheme S1 (ESI $\dagger$ ). The deprotection reaction of the BOC group was conducted using sulfuric acid in $\mathrm{MeOH}$ because the deprotection reaction using $\mathrm{HCl}$ in AcOEt did not provide a good yield.

\section{X-ray structural determinations}

Block-shaped single crystals of $\mathbf{1}$ and $\mathbf{2}$ were obtained by slow evaporation from an acetonitrile solution. Their crystal structures were successfully determined by an X-ray crystallographic analysis (Table S1, ESI $\dagger$ ). The ORTEP drawing is depicted in Fig. 2. 2 was crystallized with one molecule of acetonitrile and existed as two crystallographically independent structures (denoted as $\mathbf{2 A}$ and 2B). The bond lengths between the carbon atoms adjacent to the bridge atoms (C, Si) were 1: 1.539(3) Å, 1.543(3) Å, 2A: 1.837(5) A,

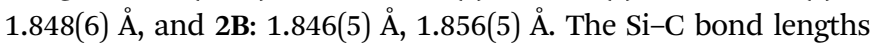
are almost the same as the reported $\mathrm{Si}-\mathrm{C}$ distance values which are $1.846 \AA$ and $1.847 \AA .^{13}$ The angles between the carbon atoms adjacent to the bridge atoms $(\mathrm{C}, \mathrm{Si})$ were 1: $108.66(15)^{\circ}, \mathbf{2 A}$ :

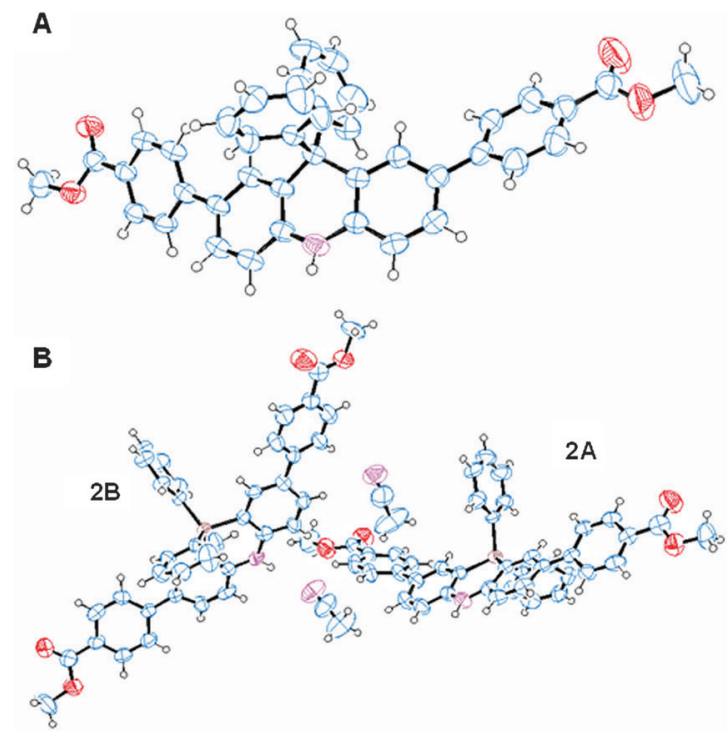

Fig. 2 ORTEP diagrams of $1(\mathrm{~A})$ and $2 \cdot \mathrm{CH}_{3} \mathrm{CN}(\mathrm{B})$ with thermal ellipsoids at the $50 \%$ level.
102.6(3) ${ }^{\circ}$, and 2B: $102.7(3)^{\circ}$. These angles depend on the atomic radius, and $\mathbf{1}$ has the larger angle. The long axes of the molecules were 1: $22.101 \AA, 2 A: 22.844 \AA$, and 2B: $22.860 \AA$. The dihedral angles between the dihydroacridine units and the 4-methoxycarbonyl units were 1: $23^{\circ}, 32^{\circ}, 2 \mathrm{~A}: 24^{\circ}, 30^{\circ}$, and $2 \mathbf{B}$ : $20^{\circ}, 27^{\circ}$.

\section{Spectroscopic properties}

The UV-vis and the fluorescence spectra of 1, 2, and 3 in various solvents are summarized in Table 1 . The maximum absorption wavelengths of 1, 2, and 3 in $\mathrm{MeOH}$ were 370, 376, and $336 \mathrm{~nm}$, respectively. Based on the UV-vis measurements, introduction of the ester group prompted a red-shift in the maximum absorption wavelength (Fig. S1, ESI $\dagger$ ). While the wavelengths of the maximum absorptions of $\mathbf{1}$ and $\mathbf{2}$ were almost the same, the molar extinction coefficients of 2 were larger than those of 1 in all solvents. 1 and 2 exhibited a fluorescence solvatochromism and the emission spectra were also shifted along with a change in the solvent polarities, while 3 did not exhibit a fluorescence solvatochromism (Fig. 3). Shorter wavelength emission in an apolar solvent and longer wavelength emission in a polar solvent were observed for $\mathbf{1}$ and 2. The wavelength of the maximum emission of 1 was red-shifted by $98 \mathrm{~nm}$ from toluene to $\mathrm{MeOH}$, while it was shifted $77 \mathrm{~nm}$ for 2 and $14 \mathrm{~nm}$ for 3 . The Stokes shifts in toluene were $53 \mathrm{~nm}$ for $\mathbf{1}, 41 \mathrm{~nm}$ for 2 and $48 \mathrm{~nm}$ for 3 . Those in MeOH were $142 \mathrm{~nm}$ for 1, $108 \mathrm{~nm}$ for 2 and $58 \mathrm{~nm}$ for 3 .

The CV measurements of 1,2 , and 3 were carried out to evaluate their electronic states. They have one reversible oxidation wave, and the half-wave potentials of 1,2 , and 3 were 0.50 , 0.53 and $0.43 \mathrm{~V}$ (versus $\mathrm{Fc} / \mathrm{Fc}^{+}$), respectively (Fig. S2, ESI $\dagger$ ). The oxidation potentials of $\mathbf{1}$ and $\mathbf{2}$ were higher than that of $\mathbf{3}$, which is explained by the introduction of the electron withdrawing ester group.

A DFT calculation with B3LYP/6-31G* was conducted to study the electronic structure (Fig. 4). Focusing on the molecular orbitals of the HOMO and LUMO, the HOMO distributes over the electron donating moiety and the LUMO is spread all over the dihydroacridine unit in 3. On the other hand, the LUMO also has distribution over the electron withdrawing ester moiety in $\mathbf{1}$ and $\mathbf{2}$. These results indicate the intramolecular CT in the excited states that results in the noticeable solvatochromism. 1 and $\mathbf{2}$ have almost the same HOMO and LUMO energy levels which are lower than those of 3 . The energy gaps of $\mathbf{1}, \mathbf{2}$, and 3 are $3.78,3.73$ and $4.25 \mathrm{eV}$, respectively. The energy gaps of 1 and 2 are

Table 1 Spectroscopic data of 1, 2, and $\mathbf{3}$ in various solvents

\begin{tabular}{|c|c|c|c|c|c|c|c|c|c|c|c|c|c|c|c|c|c|}
\hline \multirow[b]{2}{*}{ Solvent } & \multirow[b]{2}{*}{$E_{\mathrm{T}}(30)$} & \multirow[b]{2}{*}{$f(\varepsilon)$} & \multicolumn{3}{|c|}{$\underline{\lambda}_{\mathrm{Abs}, \max }[\mathrm{nm}]$} & \multicolumn{3}{|c|}{$\varepsilon\left[10^{4} \mathrm{M}^{-1} \mathrm{~cm}^{-1}\right]$} & \multicolumn{3}{|c|}{$\lambda_{\text {Em,max }}[\mathrm{nm}]$} & \multicolumn{3}{|c|}{$\Phi_{\mathrm{F}}[\%]$} & \multicolumn{3}{|c|}{$\varepsilon \times \Phi_{\mathrm{F}}\left[10^{4} \mathrm{M}^{-1} \mathrm{~cm}^{-1}\right]$} \\
\hline & & & 1 & 2 & 3 & 1 & 2 & 3 & 1 & 2 & 3 & 1 & 2 & 3 & 1 & 2 & 3 \\
\hline Toluene & 33.9 & 0.24 & 361 & 366 & 332 & 3.9 & 5.5 & 3.2 & 414 & 407 & 380 & 65 & 69 & 63 & 2.5 & 3.8 & 2.0 \\
\hline THF & 37.4 & 0.41 & 371 & 375 & 329 & 4.2 & 5.8 & 3.5 & 441 & 433 & 391 & 68 & 72 & 58 & 2.9 & 4.2 & 2.0 \\
\hline $\mathrm{CH}_{2} \mathrm{Cl}_{2}$ & 40.7 & 0.42 & 360 & 367 & 332 & 3.9 & 5.7 & 3.6 & 449 & 439 & 386 & 64 & 67 & 49 & 2.5 & 3.8 & 1.8 \\
\hline DMF & 43.2 & 0.48 & 376 & 381 & 338 & 4.1 & 5.7 & 3.4 & 472 & 462 & 399 & 60 & 62 & 69 & 2.5 & 3.5 & 2.3 \\
\hline $\mathrm{MeCN}$ & 45.6 & 0.48 & 363 & 370 & 341 & 4.1 & 4.4 & 3.3 & 466 & 458 & 393 & 54 & 56 & 58 & 2.2 & 2.5 & 1.9 \\
\hline$n$-BuOH & 49.7 & 0.46 & 378 & 382 & 339 & 3.8 & 5.6 & 3.3 & 472 & 461 & 392 & 53 & 53 & 63 & 2.0 & 3.0 & 2.1 \\
\hline EtOH & 51.9 & 0.47 & 375 & 379 & 338 & 4.1 & 4.8 & 3.5 & 478 & 467 & 391 & 45 & 50 & 62 & 1.8 & 2.4 & 2.2 \\
\hline $\mathrm{MeOH}$ & 55.4 & 0.48 & 370 & 376 & 336 & 4.2 & 5.7 & 3.5 & 512 & 484 & 394 & 17 & 25 & 57 & 0.7 & 1.4 & 2.0 \\
\hline
\end{tabular}




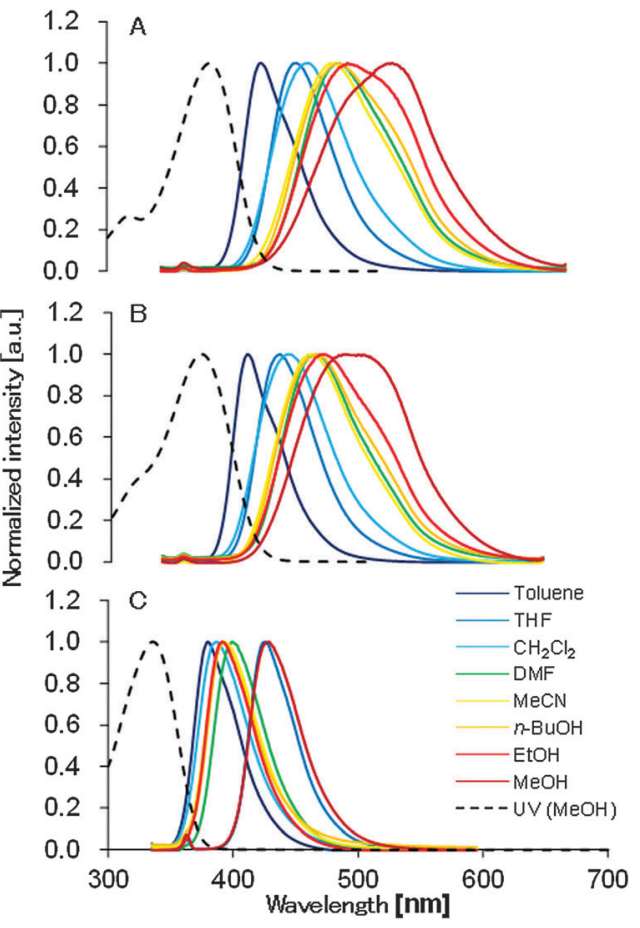

Fig. 3 Absorption (dashed line) and emission (solid line) spectra of 1 (A), $2(B)$, and $\mathbf{3}(\mathrm{C})$ in various solvents. Emission spectra were collected under $10^{-5} \mathrm{~mol} \mathrm{l}^{-1}$.

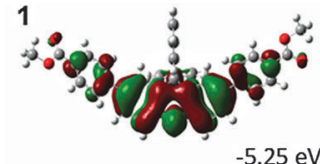

$-5.25 \mathrm{eV}$

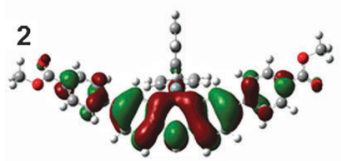

$-5.23 \mathrm{eV}$

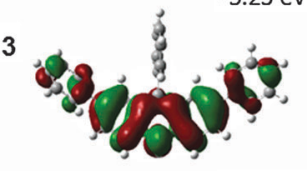

$-5.01 \mathrm{eV}$

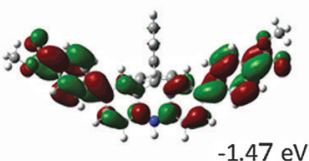

$-1.47 \mathrm{eV}$

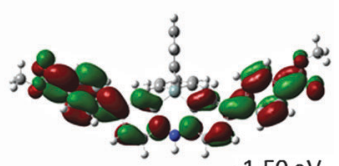

$-1.50 \mathrm{eV}$

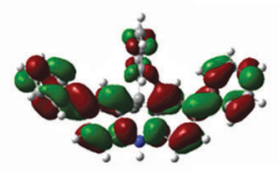

$-0.76 \mathrm{eV}$

LUMO
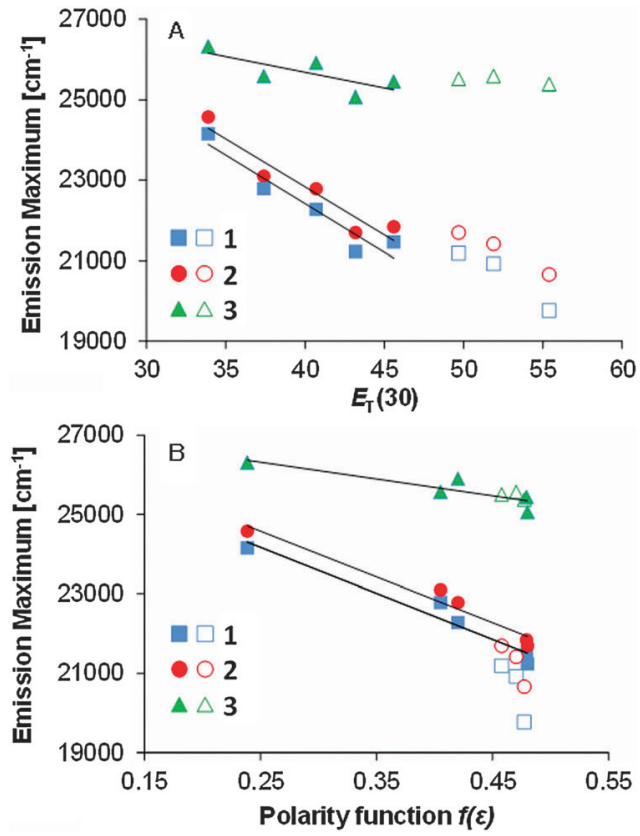

Fig. 5 The relation between the emission maxima and polarity index $E_{\mathrm{T}}(30)$ and dielectric constant function $f(\varepsilon)$ of $\mathbf{1}, \mathbf{2}$, and $\mathbf{3}$ in aprotic (solid symbols) and protic (open symbols) solvents. Linear fits were obtained only in the aprotic solvents. The slopes for graph A: $240\left(R^{2}=0.897\right), 241\left(R^{2}=\right.$ $0.906)$, and $78 \mathrm{~cm}^{-1}\left(R^{2}=0.584\right)$; graph B: $11600\left(R^{2}=0.960\right), 11600$ $\left(R^{2}=0.958\right)$, and $4200 \mathrm{~cm}^{-1}\left(R^{2}=0.784\right)$ for $\mathbf{1}, \mathbf{2}$, and 3 , respectively.

PRODAN could be achieved using the dihydroacridine-based novel fluorophore.

The data plots in the protic solvents deviate up. For a further understanding, we studied the correlation as a function of the dielectric constant $f(\varepsilon)$ which only accounts for the general dipolar interaction. ${ }^{14} \mathrm{~A}$ high linearity was also observed in the aprotic solvents. On the other hand, the data plots in the protic solvents deviate low in $\mathbf{1}$ and $\mathbf{2}$ though a high linearity was observed in all solvents in 3. Though similar phenomena were reported in 3-hydroxyflavone ${ }^{16}$ and 3-methoxychromone, ${ }^{17}$ they could be assigned to the hydrogen bonding effects between the carbonyl group and solvents. To further study the fluorescence solvatochromic behaviors of $\mathbf{1}$ and $\mathbf{2}$, the difference between the ground and excited state dipole moments $\left(\mu_{\mathrm{E}}-\mu_{\mathrm{G}}\right)$ was estimated by the Lippert-Mataga equation (eqn (1)): ${ }^{18}$

$$
\nu_{\mathrm{A}}-\nu_{\mathrm{F}}=\frac{2 \Delta f}{h c} \frac{\left(\mu_{\mathrm{E}}-\mu_{\mathrm{G}}\right)^{2}}{a^{3}}, \quad \Delta f=\frac{\varepsilon-1}{2 \varepsilon+1}-\frac{n^{2}-1}{2 n^{2}-1}
$$

smaller than that of 3. These calculations agree with the experimental results of the CV, UV-vis, and fluorescence spectra.

\section{Discussion}

We studied the correlation between the emission maxima and the solvent polarity index, $E_{\mathrm{T}}(30)^{14}$ (Fig. 5). Good correlation was found in various solvents and linear fits were used to determine the slopes, i.e., 1: $240 \mathrm{~cm}^{-1}$, 2: $241 \mathrm{~cm}^{-1}, 3: 78 \mathrm{~cm}^{-1}$. These values of $\mathbf{1}$ and $\mathbf{2}$ are comparable to that of PRODAN $\left(220 \mathrm{~cm}^{-1}\right)^{15}$ and almost the same solvatochromic properties of

in which $\nu_{\mathrm{A}}$ is the wavenumber of the absorption, $\nu_{\mathrm{F}}$ is the wavenumber of the emission, $h$ is Planck's constant, $c$ is the speed of light, $a$ is the cavity radius and $\Delta f$ is the orientation polarizability where $\Delta f$ is defined by the dielectric constant $\varepsilon$ and the refractive index $n$. The correlation between the Stokes shift and the orientation polarizability is shown in Fig. 6. Linear plots were obtained in various solvents and the slopes were $9959 \mathrm{~cm}^{-1}\left(R^{2}=0.673\right)$ for 1 and $9038 \mathrm{~cm}^{-1}\left(R^{2}=0.805\right)$ for 2 .

The change in the dipole moments $\mu_{\mathrm{E}}-\mu_{\mathrm{G}}$ was estimated as 11.0 D for 1 and $10.5 \mathrm{D}$ for 2 when $50 \%$ of the donor-acceptor 


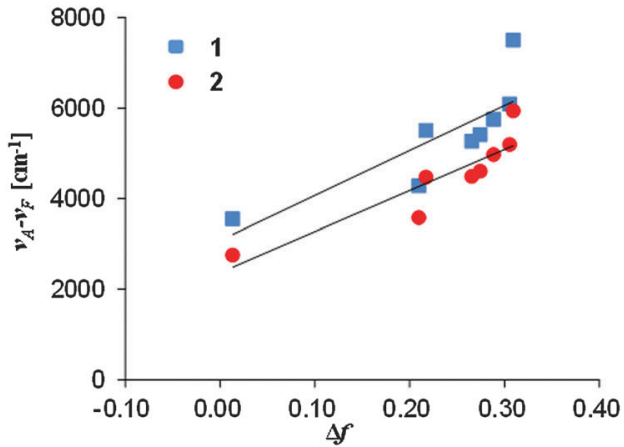

Fig. 6 The relation between the Stokes shift and the orientation polarizability of 1 and 2 .

distance was used for the cavity radius ${ }^{17}$ and as $26.1 \mathrm{D}$ for $\mathbf{1}$ and 26.2 D for 2 when $40 \%$ of the long axes of the molecular structure $^{19}$ obtained by X-ray analysis was used for the cavity radius. These values of $\mathbf{1}$ and $\mathbf{2}$ are higher than the change in the dipole moments $\mu_{\mathrm{E}}-\mu_{\mathrm{G}}$ of the representative fluorescence solvatochromic dyes, Nile Red (6.8 D) ${ }^{20}$ and PRODAN (7.9 D). ${ }^{15}$

Although the quantum yields of $\mathbf{1}$ and 2 in $\mathrm{MeOH}$ were slightly low, the quantum yields of $\mathbf{1}$ and $\mathbf{2}$ were almost over $40 \%$ in other solvents. The quantum yields of 2 were higher than those of 1 in all solvents except for $n-\mathrm{BuOH}$ though their energy gaps between the HOMO and LUMO are almost the same. We assume that this observation is due to the introduction of the $\mathrm{Si}$ atom. The quantum yield is affected by radiation and nonradiation processes. The radiation process was accelerated in the $\mathrm{Si}$ atom substituted naphthalene derivatives. ${ }^{21}$ The $\mathrm{Si}$ atom might influence radiation and non-radiation processes. The higher molar extinction coefficients of 2 compared to those of 1 might be attributed to the acceleration of the radiation process. It is known that the quantum yield depends on the type of solvent and there are a few dyes which fulfill the noticeable solvatochromism and the high quantum yield in both polar and apolar media at the same time. The quantum yield often decreases in a polar or an apolar solvent although exhibiting the properties of fluorescence solvatochromism with a high quantum yield in both polar and apolar solvents is important for use as a fluorescent probe. The fluorescence spectra of $\mathbf{1}$ and $\mathbf{2}$ showed a broad peak in $\mathrm{MeOH}$ whereas that of $\mathbf{3}$ was sharp. The experimental results might be due to the reorganization of the dihydroacridine and ester-substituted phenyl units into a twisted charge transfer excited state conformation ${ }^{22}$ or aggregation induced in polar solvents. ${ }^{15}$ It might cause the decrease of the quantum yields in $\mathrm{MeOH}$. On the other hand, the quantum yields of 3 were high in all solvents including $\mathrm{MeOH}$. A TD-DFT calculation (B3LYP/6-31G*) for 1 was performed to estimate the optimized geometry at the excited state in toluene and $\mathrm{MeOH}$ (Fig. S3, ESI $\dagger$ ). However, obvious difference was not observed between them. The fluorescence spectra of $\mathbf{3}$ showed a sharp peak in all solvents. The conformation change at the excited state might not occur in 3. 3,8-Dibutyl-6-(piperidin-1-yl)pyrene-1-carbaldehyde (PA) and 1-(3,8-dibutyl-6-(piperidin-1-yl)pyren-1-yl)butan-1-one (PK) are known as the dyes which combine these two properties. ${ }^{15}$ PRODAN, 7-diethylamino-9,9-dimethyl-9H-fluorene-2-carbaldehyde
(FR0), ${ }^{23}$ 1-(7-diethylamino-9,9-dimethyl-9H-fluoren-2-yl)-nonan1-one (FR8), ${ }^{23}$ 7-dimethylamino-9,9-dimethyl-9H-fluorene-2carbaldehyde (9FR), ${ }^{24}$ 7-dimethylamino-9,10-dihydrophenanthrene2-carbaldehyde (9Phen), ${ }^{24}$ and 1,3-diphenyl-2-[4-( $N, N$-diphenylamino)phenyl]-benzo[b]phosphole- $P$-oxide ${ }^{25}$ have been reported to show these two properties. Our spectroscopic data indicate that $\mathbf{1}$ and $\mathbf{2}$ also exhibit a fluorescence solvatochromism with high quantum yields in both polar and apolar solvents.

\section{Conclusions}

Spectroscopic properties of three dihydroacridine derivatives, 2,7-bis(4-methoxycarbonylphenyl)-9,9-diphenyl-9,10-dihydroacridine (1), 2,8-bis(4-methoxycarbonylphenyl)-10,10-diphenyl-5,10-dihydrophenazasiline (2), and 2,7,9,9-tetraphenyl-9,10-dihydroacridine (3), were investigated. These compounds exhibited relatively high quantum yields in a range of solvents (1: $17-68 \%, 2$ : $25-72 \%, 3$ : 49-69\%). To evaluate their fluorescence behavior, the correlations between the fluorescence maxima and the empirical polarity parameter, $E_{\mathrm{T}}(30)$, were studied. Linear correlations were obtained and the slopes for 1, 2, and 3 were 240,241 , and $78 \mathrm{~cm}^{-1}$, respectively. The differences between the excited and the ground state dipole moments based on the Lippert-Mataga expression were higher than those of the representative fluorescence solvatochromic dyes, Nile Red and PRODAN. The effect of the push-pull substitution in the dihydroacridine $\pi$-conjugated system was discussed. Based on the MO calculation, the CT processes from the electron donating $\mathrm{NH}$ moiety to the electron withdrawing ester moiety are ascribed to causing the positive fluorescence solvatochromism in $\mathbf{1}$ and 2.

\section{Experimental section}

The reactions were performed under $\mathrm{N}_{2}$ with the exception of the hydrogenation reaction. UV-vis and fluorescence spectra were recorded using JASCO V-650 and JASCO FP-777W, respectively. The quantum yields were determined by the absolute measurement using a Shimadzu RF-6000 attached integrating sphere unit. The $\mathrm{CV}$ measurements were performed in a $\mathrm{CH}_{2} \mathrm{Cl}_{2}$ solution with tetrabutylammonium hexafluorophosphate $(0.1 \mathrm{M})$ as the supporting electrolyte $\left(298 \mathrm{~K}, 100 \mathrm{mV} \mathrm{s}^{-1}\right.$ scan rate). The observed redox potentials were corrected against the ferrocene/ ferrocenium $\left(\mathrm{Fc} / \mathrm{Fc}^{+}\right)$couple. The X-ray diffraction data were collected by a Bruker D8 VENTURE diffractometer and refined by using SHELX-2014. Gaussian 03 programs were applied for the DFT calculations and Gaussian 09 programs were for the TD-DFT calculations.

\section{2,7-Dibromo-9,9-diphenyl-9,10-dihydroacridine (5)}

NBS (7.8 g, 4.4 eq.) dissolved in $20 \mathrm{ml}$ of DMF was added to a solution of 9,9-diphenyl-9,10-dihydroacridine $(1.7 \mathrm{~g})$ in $10 \mathrm{ml}$ of DMF. The reaction mixture was stirred at room temperature for $10 \mathrm{~h}$. An aqueous solution of $\mathrm{K}_{2} \mathrm{CO}_{3}$ was then added to the mixture. The organic phase was extracted with AcOEt and dried over $\mathrm{Na}_{2} \mathrm{SO}_{4}$. After removal of the solvent under reduced pressure, the residue was purified by silica gel column chromatography 
$\left(\mathrm{CH}_{2} \mathrm{Cl}_{2} / n\right.$-hexane $\left.=1 / 2\right)$. The collected material was further purified by recrystallization from $\mathrm{CH}_{2} \mathrm{Cl}_{2} / n$-hexane to give a white solid (2.4 g, 95\%). Mp 280-283 ${ }^{\circ} \mathrm{C} ;{ }^{1} \mathrm{H}$ NMR $(300 \mathrm{MHz}$, acetone- $\left.d_{6}\right): \delta=8.63(\mathrm{~s}, 1 \mathrm{H}), 7.35-7.27(\mathrm{~m}, 8 \mathrm{H}), 6.96-6.92$ $(\mathrm{m}, 6 \mathrm{H}), 6.86(\mathrm{~d}, J=2.4 \mathrm{~Hz}, 2 \mathrm{H}) \mathrm{ppm} ;{ }^{13} \mathrm{C} \mathrm{NMR}(75 \mathrm{MHz}$, acetone- $\left.d_{6}\right): \delta=146.0,140.2,133.1,131.1,130.8,129.9,128.9$, 127.7, 116.7, 112.5, 57.5 ppm; IR (KBr): 3389, 2360, 1665, 1598, $1472 \mathrm{~cm}^{-1}$; MS (MALDI, matrix: SA): $490[\mathrm{M}+\mathrm{H}]^{+}$; E.A. (\%): found: $\mathrm{C}$ 61.01, $\mathrm{H} \mathrm{3.33,} \mathrm{N} 2.87$, calcd for $\mathrm{C}_{25} \mathrm{H}_{15} \mathrm{Br}_{2} \mathrm{~N}$ : C 61.13, H 3.49, N 2.85 .

\section{2,7-Dibromo-9,9-diphenyl-9,10-dihydroacridine-10(9H)- carboxylic acid tert-butyl ester (6)}

A solution of 2,7-dibromo-9,9-diphenyl-9,10-dihydroacridine (1.67 g, $3.4 \mathrm{mmol}$ ) and 4-dimethylaminopyridine (145 mg; $1.2 \mathrm{mmol}, 0.35$ eq.) in THF was added to a solution of di-tertbutyl dicarbonate $(1.13 \mathrm{~g}, 5.1 \mathrm{mmol}, 1.5 \mathrm{eq}$.) in THF, and the mixture was stirred for $2 \mathrm{~h}$. After the addition of water, the resulting mixture was extracted with ethyl acetate. The organic extracts were washed with brine and dried $\left(\mathrm{Na}_{2} \mathrm{SO}_{4}\right)$, concentrated, loaded on silica gel and purified by silica gel column chromatography $\left(\mathrm{CH}_{2} \mathrm{Cl}_{2} / n\right.$-hexane $\left.=1 / 1\right)$. The collected material was further purified by recrystallization from $\mathrm{CH}_{2} \mathrm{Cl}_{2} / n$-hexane to give 6 as a white solid (1.86 g, 92\%). Mp 204-209 ${ }^{\circ} \mathrm{C} ;{ }^{1} \mathrm{H}$ NMR (300 MHz, acetone- $d_{6}$ ): $\delta=7.60(\mathrm{~d}, J=8.4 \mathrm{~Hz}, 2 \mathrm{H}), 7.54$ (dd, $J=8.9 \mathrm{~Hz}, 2.4 \mathrm{~Hz}, 2 \mathrm{H}), 7.36-7.34(\mathrm{~m}, 6 \mathrm{H}), 6.96(\mathrm{~d}, J=2.7 \mathrm{~Hz}$, 2H), 6.85-6.83 (m, 4H), 1.18 (s, 9H) ppm; ${ }^{13} \mathrm{C}$ NMR (75 MHz, $\left.\mathrm{CDCl}_{3}\right): \delta=151.1,143.2,142.6,137.8,131.1,130.0,129.6,128.1$, 127.3, 127.0, 118.3, 82.0, 58.3, 27.7 ppm; IR (KBr): 3049, 2983, 1720, 1464, 1323, $1159 \mathrm{~cm}^{-1}$; MS (MALDI, matrix: SA): 588 $[\mathrm{M}-\mathrm{H}]^{+}$; E.A. (\%): found: C 60.70, H 4.35, N 2.16, calcd for $\mathrm{C}_{30} \mathrm{H}_{25} \mathrm{Br}_{2} \mathrm{NO}_{2}$ : C 60.93, H 4.26, N 2.37.

\section{2,7-Bis(4-methoxycarbonylphenyl)-9,9-diphenyl-9,10- dihydroacridine-10(9H)-carboxylic acid tert-butyl ester (7)}

To a solution of 6 (59 mg, $0.10 \mathrm{mmol})$ in dry THF, 2-(4-methoxycarbonylphenyl)-4,4,5,5-tetramethyl-1,3,2-dioxaborolane (69 mg, $0.25 \mathrm{mmol}, 2.5 \mathrm{eq}$.), potassium carbonate $(276 \mathrm{mg}, 2.0 \mathrm{mmol}$, 20 eq.) and $\mathrm{Pd}\left(\mathrm{PPh}_{3}\right)_{4}(7 \mathrm{mg}, 6.0 \mu \mathrm{mol}, 0.06$ eq. $)$ were added and the reaction mixture was refluxed for $24 \mathrm{~h}$ under nitrogen. The reaction mixture was then poured into water and extracted with ethyl acetate. The organic extracts were washed with brine and dried with $\mathrm{Na}_{2} \mathrm{SO}_{4}$. After removal of the solvent under reduced pressure, the residue was purified by silica gel column chromatography (ethyl acetate $/ n$-hexane $=1 / 3$ ). The collected material was further purified by recrystallization from $\mathrm{CH}_{2} \mathrm{Cl}_{2} / n$-hexane to give 7 as a white solid (53 mg, 75\%). Mp 151-154 ${ }^{\circ} \mathrm{C} ;{ }^{1} \mathrm{H}$ NMR (300 MHz, acetone- $\left.d_{6}\right): \delta=8.03(\mathrm{~d}, J=8.4 \mathrm{~Hz}, 4 \mathrm{H}), 7.81(\mathrm{~d}, J=$ $9.0 \mathrm{~Hz}, 2 \mathrm{H}), 7.74(\mathrm{dd}, J=8.6 \mathrm{~Hz}, 2.1 \mathrm{~Hz}, 2 \mathrm{H}), 7.63(\mathrm{~d}, J=8.4 \mathrm{~Hz}$, $4 \mathrm{H}), 7.35-7.33(\mathrm{~m}, 6 \mathrm{H}), 7.22(\mathrm{~d}, J=2.7 \mathrm{~Hz}, 2 \mathrm{H}), 6.99-6.98(\mathrm{~m}, 4 \mathrm{H})$, $3.88(\mathrm{~s}, 6 \mathrm{H}), 1.24(\mathrm{~s}, 9 \mathrm{H}) \mathrm{ppm} ;{ }^{13} \mathrm{C} \mathrm{NMR}\left(75 \mathrm{MHz}, \mathrm{CDCl}_{3}\right): \delta=$ 166.9, 151.5, 145.1, 143.5, 141.8, 139.0, 136.2, 130.3, 130.1, 128.7, 127.9, 127.3, 127.1, 126.9, 125.9, 125.3, 81.8, 58.6, 52.1, 27.9 ppm; IR (KBr): 2950, 1720, 1608, 1478, 1329, $1280 \mathrm{~cm}^{-1}$; LRMS (EI): $m / z$ (\%): 524 (100) [M - 177 $]^{+}, 601(38)[\mathrm{M}-100]^{+}$,
701 (9) $[\mathrm{M}]^{+}$; HRMS (ESI ${ }^{+}$, quadrupole): $m / z$ calcd for $\mathrm{C}_{46} \mathrm{H}_{39} \mathrm{NO}_{6}$ $[\mathrm{M}+\mathrm{Na}]:$ 724.2670, found: 724.2676 .

\section{2,7-Bis(4-methoxycarbonylphenyl)-9,9-diphenyl-9,10- dihydroacridine (1)}

Concentrated hydrochloric acid was added to a solution of 7 (53 $\mathrm{mg}, 0.08 \mathrm{mmol}$ ) in ethyl acetate and the mixture was refluxed for $1 \mathrm{~h}$. The mixture was then cooled to room temperature and neutralized with a $\mathrm{K}_{2} \mathrm{CO}_{3}$ solution. The mixture was poured into water and extracted with ethyl acetate. The organic extracts were washed with brine and dried with $\mathrm{Na}_{2} \mathrm{SO}_{4}$. After removal of the solvent under reduced pressure, the residue was purified by silica gel column chromatography (ethyl acetate $/ n$-hexane $=1 / 2$ ). The collected material was further purified by recrystallization from $\mathrm{CH}_{2} \mathrm{Cl}_{2} / n$-hexane to give 1 as a pale yellow solid $(27 \mathrm{mg}, 56 \%)$. Mp $>300{ }^{\circ} \mathrm{C}$; ${ }^{1} \mathrm{H}$ NMR $\left(300 \mathrm{MHz}\right.$, acetone- $\left.d_{6}\right): \delta=8.81(\mathrm{~s}, 1 \mathrm{H}), 7.98(\mathrm{~d}, J=8.4$ $\mathrm{Hz}, 4 \mathrm{H}), 7.62$ (dd, $J=8.3 \mathrm{~Hz}, 2.0 \mathrm{~Hz}, 2 \mathrm{H}), 7.56(\mathrm{~d}, J=8.7 \mathrm{~Hz}, 4 \mathrm{H})$, 7.33-7.10 (m, 14H), $3.87(\mathrm{~s}, 6 \mathrm{H}) \mathrm{ppm} ;{ }^{13} \mathrm{C}$ NMR $(75 \mathrm{MHz}$, $\left.\mathrm{CDCl}_{3}\right): \delta=167.0,145.5,145.3,139.5,132.1,130.2,130.1$, 129.2, 128.4, 128.0, 127.9, 126.7, 126.3, 126.1, 114.3, 57.0, 52.0 ppm; IR (KBr): 3342, 2947, 1820, 1602, 1481, 1434, 1284, 1186, $1114 \mathrm{~cm}^{-1}$; LRMS (EI): $m / z$ (\%): 524 (100) $\left[\mathrm{M}-\mathrm{C}_{6} \mathrm{H}_{5}\right]^{+}, 601$ (28) $[\mathrm{M}]^{+}$; HRMS (EI): $m / z$ calcd for $\mathrm{C}_{41} \mathrm{H}_{31} \mathrm{NO}_{4}$ : 601.2253, found: 601.2268 .

\section{2,7,9,9-Tetraphenyl-9,10-dihydroacridine-10(9H)-carboxylic acid tert-butyl ester (8)}

8 was obtained by a method similar to 7 and was obtained as a white solid (yield: 77\%). Mp 242-246 ${ }^{\circ} \mathrm{C} ;{ }^{1} \mathrm{H}$ NMR $(300 \mathrm{MHz}$, acetone- $\left.d_{6}\right): \delta=7.75(\mathrm{~d}, J=7.5 \mathrm{~Hz}, 2 \mathrm{H}), 7.63(\mathrm{dd}, J=7.7 \mathrm{~Hz}$, $2.0 \mathrm{~Hz}, 2 \mathrm{H}), 7.48(\mathrm{~d}, J=7.8 \mathrm{~Hz}, 2 \mathrm{H}), 7.41-7.30(\mathrm{~m}, 12 \mathrm{H}), 7.14$ $(\mathrm{d}, J=2.7 \mathrm{~Hz}, 2 \mathrm{H}), 6.98-6.96(\mathrm{~m}, 4 \mathrm{H}), 1.22(\mathrm{~s}, 9 \mathrm{H}) \mathrm{ppm} ;{ }^{13} \mathrm{C} \mathrm{NMR}$ $\left(75 \mathrm{MHz}, \mathrm{CDCl}_{3}\right.$ ): $\delta=151.7,143.8,141.7,140.7,138.3,137.3$, 130.3, 128.7, 127.8, 127.1, 127.0, 127.0, 126.9, 125.6, 125.0, 81.4, 58.6, 27.8 ppm; IR (KBr): 3056, 3029, 2969, 2928, 1712, 1600, $1474 \mathrm{~cm}^{-1}$; LRMS (EI): $m / z(\%): 408$ (100) $\left[\mathrm{M}-\mathrm{C}_{11} \mathrm{H}_{7} \mathrm{O}_{2}\right]^{+}, 484$ (36) $[\mathrm{M}-\mathrm{Boc}]^{+}, 585.3$ (18) $[\mathrm{M}]^{+}$; HRMS (EI, quadrupole): $\mathrm{m} / \mathrm{z}$ calcd for $\mathrm{C}_{31} \mathrm{H}_{21} \mathrm{~N}\left[\mathrm{M}-\mathrm{C}_{11} \mathrm{H}_{7} \mathrm{O}_{2}\right]$ : 407.1674, found: 407.1683 .

\section{2,7,9,9-Tetraphenyl-9,10-dihydroacridine (3)}

$\mathbf{3}$ was obtained by a method similar to $\mathbf{1}$ and was obtained as a white solid (yield: 95\%). Mp $120{ }^{\circ} \mathrm{C} ;{ }^{1} \mathrm{H}$ NMR $(300 \mathrm{MHz}$, acetone- $\left.d_{6}\right): \delta=8.57(\mathrm{~s}, 1 \mathrm{H}), 7.51(\mathrm{~d}, J=2.3 \mathrm{~Hz}, 2 \mathrm{H}), 7.42-7.07$ $(\mathrm{m}, 22 \mathrm{H}) \mathrm{ppm} ;{ }^{13} \mathrm{C}$ NMR $\left(75 \mathrm{MHz}\right.$, acetone- $\left.d_{6}\right): \delta=147.3,141.9$, 140.6 , 133.4, 131.1, 129.6, 129.5, 128.6, 128.5, 127.3, 127.2, 126.9, 126.7, 115.3, 57.9 ppm; IR (KBr): 3392, 3056, 1602, 1474, $1303 \mathrm{~cm}^{-1}$; LRMS (MALDI, matrix: SA): 485 [M] $]^{+}$; E.A. (\%): found: C 91.22, H 5.46, N 2.62, calcd for $\mathrm{C}_{37} \mathrm{H}_{27} \mathrm{~N}$ : C 91.51, H 5.60, N 2.88 .

\section{2,4-Dibromo- $N$-(2,4-dibromophenyl)- $N$-(4-methoxybenzyl) aniline (10)}

A solution of 2,2',4,4'-tetrabromodiphenylamine (969 mg, $2.0 \mathrm{mmol}$ ) and $\mathrm{NaH}$ (54 mg, $2.2 \mathrm{mmol}, 1.1 \mathrm{eq}$.) in DMF was stirred for $1 \mathrm{~h}$. The mixture was then added to 4-methoxybenzyl 
chloride (289 $\mu \mathrm{l}, 2.1 \mathrm{mmol}, 1.06$ eq.) and stirred for $14 \mathrm{~h}$ at room temperature. Water was added to the mixture and the precipitate was filtered. The crude product was purified by silica gel column chromatography $\left(\mathrm{CH}_{2} \mathrm{Cl}_{2} / n\right.$-hexane $\left.=1 / 2\right)$. The collected material was further purified by recrystallization from $\mathrm{CH}_{2} \mathrm{Cl}_{2} / n$-hexane to give 9 as a white solid (1.09 g, 90\%). Mp 195-198 ${ }^{\circ} \mathrm{C} ;{ }^{1} \mathrm{H}$ NMR (300 MHz, $\left.\mathrm{CDCl}_{3}\right): \delta=7.70(\mathrm{~d}, J=$ $2.4 \mathrm{~Hz}, 2 \mathrm{H}), 7.36(\mathrm{~d}, J=8.4 \mathrm{~Hz}, 2 \mathrm{H}), 7.26(\mathrm{dd}, J=8.9 \mathrm{~Hz}, 2.3 \mathrm{~Hz}$, $2 \mathrm{H}), 6.79$ (d, $J=8.4 \mathrm{~Hz}, 4 \mathrm{H}), 4.68(\mathrm{~s}, 2 \mathrm{H}), 3.75$ (s, 3H) ppm; ${ }^{13} \mathrm{C}$ NMR (75 MHz, $\mathrm{CDCl}_{3}$ ): $\delta=158.7,145.8,136.6,130.9,128.7$, 128.6, 126.4 121.9, 117.2, 113.8, 56.0, 55.1 ppm; IR (KBr): 2930, 1509, 1464, 1240, $1175 \mathrm{~cm}^{-1}$; LRMS (MALDI, matrix: SA): 600 $[\mathrm{M}]^{+}$; E.A. (\%): found: $\mathrm{C} 40.01, \mathrm{H} 2.63, \mathrm{~N} 2.20$, calcd for $\mathrm{C}_{20} \mathrm{H}_{15} \mathrm{Br}_{4} \mathrm{NO}$ : C 39.71, H 2.50, N 2.32.

\section{2,8-Dibromo-5-(4-methoxybenzyl)-10,10-diphenyl-5,10- dihydrophenazasiline (11)}

To a solution of 10 (605 mg, $1.0 \mathrm{mmol})$ in $19 \mathrm{ml}$ of $\mathrm{Et}_{2} \mathrm{O}, n$-BuLi (2.6 $\mathrm{M}$ in $n$-hexane solution, $0.84 \mathrm{ml}, 2.1 \mathrm{mmol}, 2.1$ eq.) was added dropwise at $0{ }^{\circ} \mathrm{C}$ and the mixture was stirred for $0.5 \mathrm{~h}$. $\mathrm{SiPh}_{2} \mathrm{Cl}_{2}$ (0.25 ml, $1.2 \mathrm{mmol}, 1.2 \mathrm{eq}$.) was next added to the reaction mixture. The mixture was warmed to room temperature and stirred overnight. Water was added, and the resulting mixture was extracted with ethyl acetate. The organic extracts were washed with brine, dried with $\mathrm{Na}_{2} \mathrm{SO}_{4}$ and concentrated. The residue was purified by silica gel column chromatography $\left(\mathrm{CH}_{2} \mathrm{Cl}_{2} / n\right.$-hexane $\left.=1 / 3\right)$. The collected material was further purified by recrystallization from $\mathrm{CH}_{2} \mathrm{Cl}_{2} / n$-hexane to give $\mathbf{1 1}$ as a white solid (483 mg, 77\%). Mp 204-208 ${ }^{\circ} \mathrm{C} ;{ }^{1} \mathrm{H}$ NMR (300 MHz, $\mathrm{CDCl}_{3}$ ): $\delta=$ 7.53-7.33 (m, 14H), $7.01(\mathrm{~d}, J=8.4 \mathrm{~Hz}, 2 \mathrm{H}), 6.88(\mathrm{~d}, J=8.7 \mathrm{~Hz}, 2 \mathrm{H})$, $6.82(\mathrm{~d}, J=8.4 \mathrm{~Hz}, 2 \mathrm{H}), 5.08(\mathrm{~s}, 2 \mathrm{H}), 3.80$ (s, 3H) ppm; ${ }^{13} \mathrm{C}$ NMR (75 MHz, $\mathrm{CDCl}_{3}$ ): $\delta=158.7,148.9,137.1,136.1,133.5,132.6,130.2$, 128.5, 128.2, 127.4, 121.7, 118.5, 114.3, 114.0, 55.3, 55.3 ppm; IR (KBr): 3066, 2954, 1509, 1449, 1394, 1291, $1220 \mathrm{~cm}^{-1}$; LRMS (MALDI, matrix: SA): 625 [M] ${ }^{+}$; E.A. (\%): found: C 61.24, H 4.08, N 2.08, calcd for $\mathrm{C}_{32} \mathrm{H}_{25} \mathrm{Br}_{2}$ NOSi: C 61.26, H 4.02, N 2.33.

\section{2,8-Dibromo-10,10-diphenyl-5,10-dihydrophenazasiline (12)}

Pd black (15 mg) and 11 (44 mg, $0.09 \mathrm{mmol}$ ) were placed in a one-necked flask and dichloromethane was then added. Nitrogen displacement was next conducted. The mixture was stirred for $15 \mathrm{~h}$ after the $\mathrm{H}_{2}$ displacement. Nitrogen was again displaced. The mixture was then filtered through Celite. Dichloromethane was added to carry out a conventional separation treatment. The organic extracts were washed with brine and dried with $\mathrm{Na}_{2} \mathrm{SO}_{4}$. After removal of the solvent under reduced pressure, the residue was purified by silica gel column chromatography $\left(\mathrm{CH}_{2} \mathrm{Cl}_{2} / n\right.$-hexane $\left.=1 / 3\right)$. The collected material was further purified by recrystallization from $\mathrm{CH}_{2} \mathrm{Cl}_{2} / n$-hexane to give 12 as a white solid (25 mg, 63\%). Mp 254-257 ${ }^{\circ} \mathrm{C} ;{ }^{1} \mathrm{H}$ NMR $(300 \mathrm{MHz}$, acetone- $\left.d_{6}\right): \delta=9.01(\mathrm{~s}, 1 \mathrm{H}), 7.60-7.57(\mathrm{~m}, 6 \mathrm{H}), 7.51-7.44$ $(\mathrm{m}, 8 \mathrm{H}), 7.09$ (d, $J=9.0 \mathrm{~Hz}, 2 \mathrm{H}) \mathrm{ppm} ;{ }^{13} \mathrm{C} \mathrm{NMR}(75 \mathrm{MHz}$, $\left.\mathrm{CDCl}_{3}\right): \delta=144.8,137.8,135.8,133.9,133.8,130.1,128.2,117.4$, 115.9, 112.8 ppm; IR (KBr): 3403, 1595, 1457, 1370, 1327, $1231 \mathrm{~cm}^{-1}$; LRMS (MALDI, matrix: SA): $505[\mathrm{M}]^{+}$; E.A. (\%): found: C 56.61, $\mathrm{H}$ 3.41, N 2.64, calcd for $\mathrm{C}_{24} \mathrm{H}_{17} \mathrm{Br}_{2} \mathrm{NSi}$ : C 56.82, H 3.38, N 2.76.
2,8-Dibromo-10,10-diphenyl-5,10-dihydrophenazasiline5(10H)-carboxylic acid tert-butyl ester (13)

13 was obtained by a method similar to 6 and was obtained as a white solid. Yield: 89\%; Mp 201-204 ${ }^{\circ} \mathrm{C} ;{ }^{1} \mathrm{H}$ NMR $(300 \mathrm{MHz}$, $\left.\mathrm{CDCl}_{3}\right): \delta=7.54-7.36(\mathrm{~m}, 16 \mathrm{H}), 1.15(\mathrm{~s}, 9 \mathrm{H}) \mathrm{ppm} ;{ }^{13} \mathrm{C} \mathrm{NMR}$ $\left(75 \mathrm{MHz}, \mathrm{CDCl}_{3}\right): \delta=152.5,145.8,136.2,136.1,134.3,132.6$, 130.6, 129.4 128.3, 120.0, 81.6, 27.8 ppm; IR (KBr): 3069, 2874, 2930, 1714, 1450, 1369, 1312, $1248 \mathrm{~cm}^{-1}$; LRMS (MALDI, matrix: SA): $605[\mathrm{M}]^{+}$; E.A. (\%): found: C 57.12, H 4.20, N 2.13, calcd for $\mathrm{C}_{29} \mathrm{H}_{25} \mathrm{Br}_{2} \mathrm{NO}_{2}$ Si: C 57.34, H 4.15, N 2.31.

\section{2,8-Bis(4-methoxycarbonylphenyl)-10,10-diphenyl-5,10- dihydrophenazasiline-5(10H)-carboxylic acid tert-butyl ester}

(14)

14 was prepared by a method similar to 7 and was obtained as a white solid. Yield: 51\%; Mp 120-122 ${ }^{\circ} \mathrm{C} ;{ }^{1} \mathrm{H}$ NMR $(300 \mathrm{MHz}$, acetone- $\left.d_{6}\right): \delta=8.04(\mathrm{~d}, J=8.7 \mathrm{~Hz}, 4 \mathrm{H}), 7.84-7.83(\mathrm{~m}, 4 \mathrm{H}), 7.74-$ $7.71(\mathrm{~m}, 6 \mathrm{H}), 7.66-7.63(\mathrm{~m}, 4 \mathrm{H}), 7.52-7.45(\mathrm{~m}, 6 \mathrm{H}), 3.88(\mathrm{~s}, 6 \mathrm{H})$, $1.26(\mathrm{~s}, 9 \mathrm{H}) \mathrm{ppm} ;{ }^{13} \mathrm{C} \mathrm{NMR}\left(75 \mathrm{MHz}, \mathrm{CDCl}_{3}\right): \delta=166.9,153.3$, 148.5, 145.6, 137.8, 137.0, 133.1, 133.1, 131.5, 131.4, 130.8, 129.9, 129.4, 129.3, 129.2, 127.8, 81.6, 52.3, 28.1 ppm; IR (KBr): 2976, 2950, 1719, 1609, 1457, 1432, 1321, 1278, 1161, $1110 \mathrm{~cm}^{-1}$; LRMS (EI): $m / z(\%): 540(20)[\mathrm{M}-177]^{+}, 617(80)[\mathrm{M}-100]^{+}, 662$ (100) $[\mathrm{M}-55]^{+}, 717$ (11) $[\mathrm{M}]^{+}$; HRMS (ESI ${ }^{+}$, quadrupole): $\mathrm{m} / \mathrm{z}$ calcd for $\mathrm{C}_{45} \mathrm{H}_{39} \mathrm{NO}_{6} \mathrm{Si}[\mathrm{M}+\mathrm{Na}]$ : 740.2439, found: 740.2446 .

\section{2,8-Bis(4-methoxycarbonylphenyl)-10,10-diphenyl-5,10- dihydrophenazasiline (2)}

$\mathrm{H}_{2} \mathrm{SO}_{4}$ was added to a solution of $14(100 \mathrm{mg}, 0.14 \mathrm{mmol})$ in $\mathrm{MeOH}$ and the mixture was stirred at room temperature for $3 \mathrm{~h}$. The mixture was then neutralized with a $\mathrm{K}_{2} \mathrm{CO}_{3}$ solution. The mixture was poured into water and extracted with ethyl acetate. The organic extracts were washed with brine and dried with $\mathrm{Na}_{2} \mathrm{SO}_{4}$. After removal of the solvent under reduced pressure, the residue was purified by silica gel column chromatography (ethyl acetate $/ n$-hexane $=1 / 2$ ). The collected material was further purified by recrystallization from $\mathrm{CH}_{2} \mathrm{Cl}_{2} / n$-hexane to give 2 as a pale yellow solid (56 mg, 65\%); $\mathrm{Mp} 272-274{ }^{\circ} \mathrm{C}$; ${ }^{1} \mathrm{H}$ NMR $\left(300 \mathrm{MHz}\right.$, acetone- $\left.d_{6}\right): \delta=9.16(\mathrm{~s}, 1 \mathrm{H}), 8.02(\mathrm{~d}, J=8.7$ $\mathrm{Hz}, 4 \mathrm{H}), 7.95(\mathrm{~d}, J=2.1 \mathrm{~Hz}, 2 \mathrm{H}), 7.81(\mathrm{dd}, J=8.7 \mathrm{~Hz}, 2.1 \mathrm{~Hz}, 2 \mathrm{H})$, 7.74-7.68 (m, 10H), 7.45-7.42 (m, 6H), 7.29 (d, $J=8.1 \mathrm{~Hz}, 2 \mathrm{H})$, $3.88(\mathrm{~s}, 6 \mathrm{H}) \mathrm{ppm} ;{ }^{13} \mathrm{C} \mathrm{NMR}\left(75 \mathrm{MHz}, \mathrm{CDCl}_{3}\right): \delta=167.0,146.2$, 145.1 , 135.9, 134.9, 134.7, 131.7, 130.1, 129.9, 129.8, 128.1, 128.1, 126.2, 116.2, 114.0, 52.1; IR (KBr): 3423, 1720, 1597, 1460, 1434, $1285 \mathrm{~cm}^{-1}$; LRMS (EI): $m / z$ (\%): 540 (20) $\left[\mathrm{M}-\mathrm{C}_{6} \mathrm{H}_{5}\right]^{+}$, 617 (80) $[\mathrm{M}]^{+}$; HRMS (ESI-, quadrupole): $\mathrm{m} / \mathrm{z}$ calcd for $\mathrm{C}_{40} \mathrm{H}_{31} \mathrm{NO}_{4} \mathrm{Si}[\mathrm{M}-\mathrm{H}]:$ 616.1950, found: 616.1962.

\section{Acknowledgements}

This work was partly supported by a Grant-in-Aid for Scientific Research (No. 25620066) from MEXT, Japan, and the MEXTSupported Program for the Strategic Research Foundation at Private Universities, 2012-2016. 


\section{References}

1 (a) J. R. Lakowicz, in Principles of Fluorescence Spectroscopy, Springer Science + Business, New York, 2010; (b) B. Valeur, in Molecular Fluorescence, Princeples and Applications, WileyVCH, New York, 2002; (c) A. P. de Silva, H. Q. N. Gunaratne, T. Gunnlaugsson, A. J. M. Huxley, C. P. McCoy, J. T. Rademacher and T. E. Rice, Chem. Rev., 1997, 97, 1515; (d) K. A. Willets, S. Y. Nishimura, P. J. Schuck, R. J. Twieg and W. E. Moerner, Acc. Chem. Res., 2005, 38, 549; (e) M. S. T. Gonçalves, Chem. Rev., 2009, 109, 190; $(f)$ R. W. Sinkeldam, N. J. Greco and Y. Tor, Chem. Rev., 2010, 110, 2579; ( $g$ ) Z. Yang, J. Cao, Y. He, J. H. Yang, T. Kim, X. Peng and J. S. Kim, Chem. Soc. Rev., 2014, 43, 4563.

2 G. Saroja, T. Soujanya, B. Ramachandram and A. Samanta, J. Fluoresc., 1998, 8, 405.

3 (a) G. Weber and F. J. Farris, Biochemistry, 1979, 18, 3075; (b) A. Balter, W. Nowak, W. Pawelkiewicz and A. Kowalczyk, Chem. Phys. Lett., 1988, 8, 405.

4 G. Loving and B. Imperiali, J. Am. Chem. Soc., 2008, 130, 13630.

5 (a) M. E. Vazquez, J. B. Blanco and B. Imperiali, J. Am. Chem. Soc., 2005, 127, 1300; (b) A. R. Katritzky and T. Narindoshvili, Org. Biomol. Chem., 2009, 7, 627.

6 (a) S. Fery-Forgues, J.-P. Fayet and A. Lopez, J. Photochem. Photobiol., A, 1993, 70, 229; (b) B. E. Cohen, A. Pralle, X. Yao, G. Swaminath, C. S. Gandhi, Y. N. Jan, B. K. Kobilka, E. Y. Isacoff and L. Y. Jan, Proc. Natl. Acad. Sci. U. S. A., 2005, 102, 965; (c) P. D. Zoon and A. M. Brouwer, ChemPhysChem, 2005, 6, 1574; (d) Z. Lu, S. J. Lord, H. Wang, W. E. Moerner and R. J. Twieg, J. Org. Chem., 2006, 71, 9651; (e) S. J. Load, Z. Lu, H. Wang, K. A. Willets, P. J. Schuck, H.-I. D. Lee, S. Y. Nishimura, R. J. Twieg and W. E. Moerner, J. Phys. Chem. A, 2007, 111, 8934; $(f)$ K. Baathulaa, Y. Xu and X. Qian, J. Photochem. Photobiol., A, 2010, 216, 24; (g) A. Fakhari M. and S. E. Rokita, Chem. Commun., 2011, 47, 4222; (h) E. Benedetti, L. S. Kocsis and K. M. Brummond, J. Am. Chem. Soc., 2012, 134, 12418; (i) A. G. Gilani, M. Moghadam and M. S. Zakerhamidi, Dyes Pigm., 2012, 92, 1052; $(j)$ L. Giordano, V. V. Shvadchak, J. A. Fauerbach, E. A. Jares-Erijman and T. M. Jovin, J. Phys. Chem. Lett., 2012, 3, 1011; ( $k$ ) Y. Kubota, Y. Sakuma, K. Funabiki and M. Matsui, J. Phys. Chem. A, 2014, 118, 8717; (l) A. Tigreros, A. Ortiz and B. Insuasty, Dyes Pigm., 2014, 111, 45; (m) S. Kato, T. Furuya, M. Nitani, N. Hasebe, Y. Le, Y. Aso, T. Yoshihara, S. Tobita and Y. Nakamura, Chem. - Eur. J., 2015, 21, 3115.

7 (a) S. Yamaguchi and K. Tamao, Bull. Chem. Soc. Jpn., 1996, 69, 2327; (b) S. Kyushin, M. Ikarugi, M. Goto, H. Hiratsuka and H. Matsumoto, Organometallics, 1996, 15, 1067; (c) S. Satoh, H. Suzuki, Y. Kimata and A. Kuriyama, Synth.
Met., 1996, 79, 97; (d) S. Yamaguchi, S. Akiyama and K. Tamao, Organometallics, 1998, 17, 4347; (e) H. J. Tracy, J. L. Mullin, W. T. Klooster, J. A. Martin, J. Haug, S. Wallace, I. Rudloe and K. Watts, Inorg. Chem., 2005, 44, 2003; (f) M. Shimizu, H. Tatsumi, K. Mochida, K. Oda and T. Hiyama, Chem. - Asian J., 2008, 3, 1238; (g) Y. Yabusaki, N. Ohshima, H. Kondo, T. Kusamoto, Y. Yamanoi and H. Nishihara, Chem. - Eur. J., 2010, 16, 5581; (h) T. Agou, M. D. Hossain and T. Kawashima, Chem. - Eur. J., 2010, 16, 368; (i) M. Shimizu and T. Hiyama, Synlett, 2012, 973.

8 (a) M. Yao, S. Asakura, M. Abe, H. Inoue and N. Yoshioka, Cryst. Growth Des., 2005, 5, 413; (b) M. Yao, H. Inoue and N. Yoshioka, Chem. Phys. Lett., 2005, 402, 11.

9 R. Suzuki, R. Tada, Y. Miura and N. Yoshioka, J. Mol. Struct., 2016, 1106, 399.

10 T. L. Andrew and T. M. Swager, J. Org. Chem., 2011, 76, 2976. 11 S. Kajigaeshi, T. Kakinami, K. Inoue, M. Kondo, H. Nakamura, M. Fujikawa and T. Okamoto, Bull. Chem. Soc. Jpn., 1988, 61, 597.

12 H. Gilman and E. A. Zuech, J. Am. Chem. Soc., 1960, 82, 2522. 13 M. E. Lee, H. M. Cho, C. H. Kim and W. Ando, Organometallics, 2001, 20, 1472.

14 C. Reichardt, Chem. Rev., 1994, 94, 2319.

15 Y. Niko, S. Kawauchi and G. Konishi, Chem. - Eur. J., 2013, 19, 9760.

16 A. S. Klymchenko and A. P. Demchenko, Phys. Chem. Chem. Phys., 2003, 5, 461.

17 O. A. Kucherak, L. Richert, Y. Mély and A. S. Klymchenko, Phys. Chem. Chem. Phys., 2012, 14, 2292.

18 (a) E. L. Lippert, Organic Molecular Photophysics, Wiley, New York, 1975; (b) N. Mataga and T. Kubota, Molecular Interactions and Electronic Spectra, Dekker, New York, 1970.

19 S. I. van Dijk, P. G. Wiering, C. P. Groen, A. M. Brouwer, J. W. Verhoeven, W. Schuddeboom and J. M. Warman, J. Chem. Soc., Faraday Trans., 1995, 91, 2107.

20 A. K. Dutta, K. Kamada and K. Ohta, J. Photochem. Photobiol., A, 1996, 93, 57.

21 S. Kyushin, Y. Ishikita, H. Matsumoto, H. Horiuchi and H. Hiratsuka, Chem. Lett., 2006, 35, 64.

22 (a) Z. R. Grabowski, K. Rotkiewicz and W. Rettig, Chem. Rev., 2003, 103, 3899; (b) H. Kotaka, G. Konishi and K. Mizuno, Tetrahedron Lett., 2010, 51, 181.

23 O. A. Kucherak, P. Didier, Y. Mély and A. S. Klymchenko, J. Phys. Chem. Lett., 2010, 1, 616.

24 S. Sasaki, Y. Niko, A. S. Klymchenko and G. Konishi, Tetrahedron, 2014, 70, 7551.

25 E. Yamaguchi, C. Wang, A. Fukazawa, M. Taki, Y. Sato, T. Sasaki, M. Ueda, N. Sasaki, T. Higashiyama and S. Yamaguchi, Angew. Chem., Int. Ed., 2015, 54, 4539. 